\title{
Analysis of Bending Response of Tubes Conveying Fluid by the Method of Characteristics
}

\author{
${ }^{1}$ Ahmed Al-Rajihy and ${ }^{2}$ Mohanned Kadhom \\ ${ }^{1}$ Ahmed Abdullah Hassan Al-Rajihy, professor of Applied Mechanics, University of Babylon, Department of Automobiles Engineering, College of Engineering - \\ Almusayab, Iraq. \\ 2Mohanned Kareem Kadhom, University of Babylon, Department of Mechanical Engineering, College of Engineering, Hindia, Iraq
}

Correspondence Author: Ahmed Abdullah Hassan Al-Rajihy, University of Babylon, Department of Automobiles Engineering, College of EngineeringAlmusayab, Iraq.

E-mail: ahmmed_abuluca1963@yahoo.com, met.ahmed.abd@uobabylon.edu.iq

Received date: 10 January 2018, Accepted date: 28 February 2018, Online date: 10 March 2018

Copyright: (c) 2018 Ahmed Al-Rajihy and Mohanned Kadhom. This is an open-access article distributed under the terms of the Creative Commons Attribution License, which permits unrestricted use, distribution, and reproduction in any medium, provided the original author and source are credited.

\begin{abstract}
The present work deals with the dynamical response of tubes conveying flowing fluid and subjected to external impact loading using the method of characteristics as an approach of solution. Tubes has many important applications such as fuel lines, hydraulic lines, heat exchangers and transportation of fluids according to the demand. The dynamical analysis of tubes conveying fluid is of important necessity to insure safe operation. The work is focused on the investigation of the effect of fluid flow on the bending response of a cantilever pipe subjected to lateral impact force. The governing equation is derived according to Newton's second law. The approach of solution depends on the wave propagation in one-dimensional structural element using the Method of characteristics. The LabVIEW software was used to analyze the signals picked up from the accelerometers, impact hammer and strain gages that used in the experiments. A calibrated ultrasonic flow meter was used to measure the flow velocity. The results show that increasing the flow velocity results in reducing the amplitude of bending moment response to the impact lateral force by about $9 \%$. The results also show that the time required to attenuate the amplitude of the bending moment response by $90 \%$ is about $48 \%$. These effects are due to the Coriolis Effect which depends on the flow velocity of fluid and lateral velocity of tube. This study concludes that the velocity of fluid flow has an important influence on the dynamic response of tubes conveying fluid. Also we found that the method of characteristics (MOC) is found to be a suitable approach for idealizing the wave propagation in fluid-structure interaction elements.
\end{abstract}

Key words: Bending response, dynamics of tubes, Method of characteristics, Wave propagation

\section{INTRODUCTION}

Piping systems are widely utilized to convey fluids in different fields such as crude oil pipelines transmission power generation plants, chemical plants piping, fuel pipes in engine systems, air conditioners, heat exchangers, hydropower systems and biological engineering [1]. Piping systems are subjected to different types of effects such earthquake ground motion, pulsating flow, repeated loads due to start-up and shut-down trigger motions [2,3]. Piping systems also may be subjected to impact loads which cause longitudinal and bending stress waves [2]. These effects may lead to mechanical failure or system instability. Therefore the dynamics of fluid structure interaction has received a considerable attention over the last half century, partly because the applications, and partly because it is an interesting fundamental problem in applied mechanics.

The dynamical behavior of tubes conveying fluid have been considered by many investigators using different methods of solution. The first study in this field was performed by Ashley and Havil [4] when they studied the transvers vibrations of oil pipelines by considering the problem as a simply supported pipe. Housner [5] studied this problem using an approximate power series to solve the equation of motion, neglecting the effect of internal pressure. He concluded, as [4] concluded, that increasing the fluid velocity reduced the natural frequencies of the system, and the system loses stability by buckling.

In 1993, Zhang Xi-de et al [6], show that the equation derived by [5] was approximate and they gave the necessary correction to it.

Al-Rajihy [7] studied the coupled effects of thermal force and mispositioning of the intermediate supports on the dynamical behavior of continuous pipes supported by periodical supports. The equation of motion for the pipe was derived according to simple beam theory and the governing equation was solved analytically. He concluded that the pipe becomes unstable when the thermal force reached a value known as critical thermal force, and the value of the mispositioning of the intermediate supports.

The dynamics of Y-shaped tube with clamed end conditions was studied by Al-Maaitah and Kardsheh, [8]. The mathematical model is resolved by Galerkin method. They investigate the effect of branching angle and geometrical configuration on the natural frequency and mode shape. The researcher concludes that increasing the flow velocity results in decreasing the natural frequencies for the first three modes.

Al-Rajihy and Alwan [9] presented the vibrational characteristics of a Y-shaped tube conveying flowing fluid. The tube is considered to be composed of 3straight tube segments matched at the intermediate junction. The governing equation of straight tube conveying fluid was used with each of the three segments. This work introduced the clamped-pinned and clamped free boundary conditions which were not considered by Al-Maaitah, and Kardsheh, [8]. The coupled effects of the type of boundary conditions, angle between the two Y-segments, fluid velocity and length ratio of segments on the dynamics of the tube were studied. They concluded that the Y-tube loses its stability at flow velocity higher than that for straight tube of the same characteristics.

Long and Fuzhen [10] investigated the dynamics of supported pipes conveying pulsating fluid using precise integration method. The results show that the PIM is an efficient and rapid approach for flow induced dynamic analysis of supported pipes. 
Ibrahim [11] gave a review article presents an overview of mechanics of pipes conveying fluid and related problems such as the fluid elastic instability under conditions of turbulence in nuclear power plants.

The behavior of structural elements under impact or impulsive loads was considered many researchers using the method of characteristics or the analytical method Leorand and Budiansky [12]. Leonard analyzed the traveling waves in beams under lateral loading using the method of characteristics, governed by Timoshenko beam theory, assuming that the shear and bending waves are equal.

Chou [13] utilized the method of characteristics to treat the Timoshenko's beam equation as a system of second order differential equations in an approach capable of dealing with semi-infinite members having discontinuities along their characteristics.

Almousawi, Harrison [14] investigated the numerical solution of the transient flexural wave propagation in finite circular beams with discontinuities in crosssectional area by the method of characteristics.

Vardy and Al-Sarraj [15] used the method of characteristics to simulate axial, flexural and torsional vibrations of single structural members supporting discrete masses.

Al-Da'ami et al [16] presented the nonlinear large-angle bending dynamic analysis of curved beams by modeling wave's transmission along curved members. The approach depends on the wave propagation in one-dimensional structural element using the method of characteristics. Timoshenko's beam theory, which includes transverse shear deformation and rotary inertia effects, was adopted in this analysis.

The researchers who used the method of characteristics concluded that the values of stresses raised in structures under impact or impulsive loads depend on the geometry of structure, value of load, type of load and period of loading. Also they found that the method of characteristics (MOC) is a suitable method for idealizing the wave propagation inside structural systems.

From the available researches deals with the dynamics of tubes conveying fluid, and those followed the method of characteristics we found that the method of characteristics is applied to structures free of fluid. The contribution of this work is to solve the problem of transient response of tubes conveying fluids subjected to lateral impact force by the method of characteristics. The validity of this approach in solving the problems of dynamical behavior of tubes conveying fluid will be checked by some experiments.

Elastic Stress Wave

\section{FORMULATION}

In the present work, the dynamic response of an elastic tube conveying fluid subjected to dynamic load over a very short period is considered in terms of elastic wave propagation theory. The governing equations will be derived according to Newton's second law, and Timoshenko's beam theory is considered to be approximated that contains the essential features of the exact theory in a simplified form [13].

In the present the following two assumptions are considered;

1- The deformations are very small so that the change of element geometry can be neglected.

2- The deformation caused by loads will be recovered when the load is removed.

A- Elastic Flexural Waves in Prismatic Tubes:

Consider the transvers deformation of an element of a prismatic tube conveying fluid shown in Fig. 1;

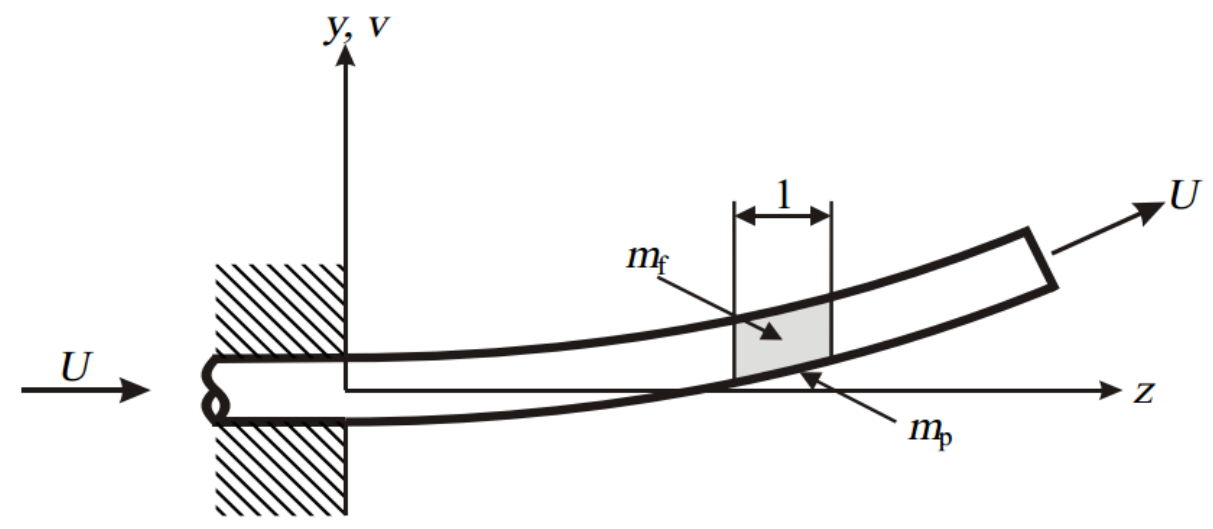

Fig. 1: Schematic of cantilever tube conveying flowing fluid

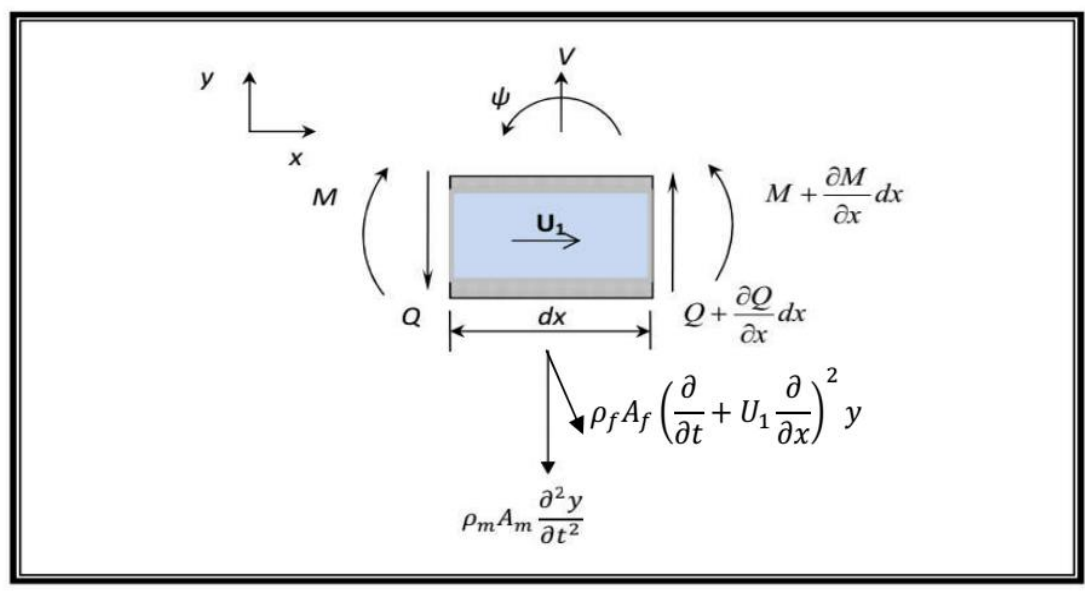

Fig. 2: Free body diagram of the tube element

The dynamic equilibrium equation of forces along $y$-direction being: 
$\frac{\partial Q}{\partial x}++\rho_{m} A_{m} \frac{\partial V}{\partial t}+\rho_{f} A_{f}\left(\frac{\partial}{\partial t}+U_{1} \frac{\partial}{\partial x}\right)^{2} y=0$

This equation can be rewritten in the form;

$\frac{\partial Q}{\partial x}+\left(\rho_{m} A_{m}+\rho_{f} A_{f}\right) \frac{\partial V}{\partial t}+2 \rho_{f} A_{f} \mathrm{U}_{1}^{\frac{\partial^{2} y}{\partial t \partial x}}+\rho_{f} A_{f}\left(\mathrm{U}_{1}\right)^{2} \frac{\partial^{2} y}{\partial x^{2}}=0$

Where the term $\left(\rho_{m} A_{m}+\rho_{f} A_{f}\right) \frac{\partial V}{\partial t}$ represent the dual inertia effect of tube material and fluid, the term $\left(2 \rho_{f} A_{f} \mathrm{U}_{1} \frac{\partial^{2} y}{\partial t \partial x}\right)$ represent Coriolis effect, and the last term $\left(\rho_{f} A_{f}\left(\mathrm{U}_{1}\right)^{\frac{\partial^{2} y}{\partial x^{2}}}\right)$ represent centrifugal effect.

The equation of moment equilibrium is;

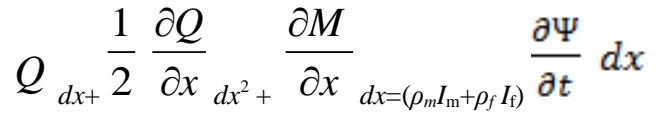

The term ( $\left.\frac{1}{2} \frac{\partial Q}{\partial x} d x^{2}\right)$ is of negligible effect, and then (3) becomes:

$\frac{\partial M}{\partial x}+Q_{=\left(\rho_{m} I_{\mathrm{m}}+\rho_{f} I_{\mathrm{f}}\right)} \frac{\partial \psi}{\partial t}$

The material property in shear is given by (Almousawi, S.K.G.M.M., H.R. Harrison, 1988);

$\frac{\partial Q}{\partial t}=K G A\left(\frac{\partial V}{\partial x_{-}} \psi\right)$

And the material property in bending is given by (Almousawi, S.K.G.M.M., H.R. Harrison, 1988);

$\frac{\partial M}{\partial t}=E I \frac{\partial \psi}{\partial x}$

Equations $2 \& 5$ and $4 \& 6$ are two pairs of hyperbolic partial differential equations relating shear force with the lateral velocity and moment with the angular velocity respectively. Each pair can be expressed as ordinary differential equation provided that their range of applicability is restricted to certain characteristic directions in the $x$ - $t$ plane as shown in Figure (3). The ordinary differential equations can be represented by the following two equations as;

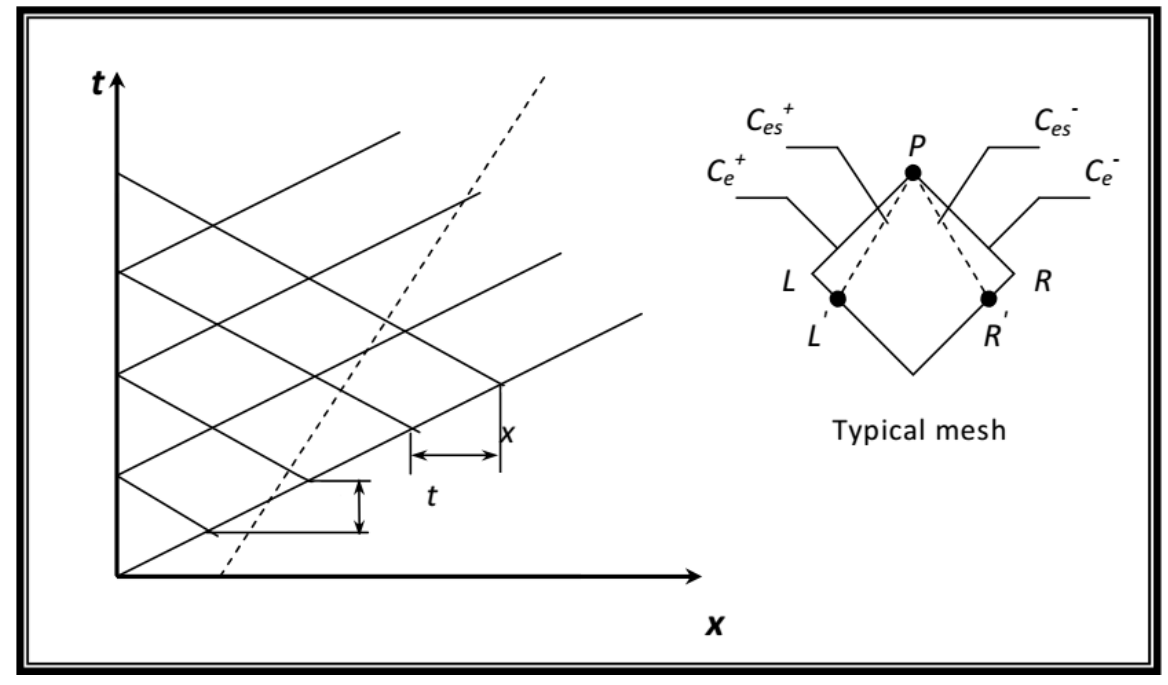

Fig. 3: Characteristic network and typical mesh of elastic flexural waves

$$
\begin{aligned}
& \text { - Shear along } \mp_{C_{e s}}, \\
& \frac{d Q}{d t} \pm{ }_{\left(\rho_{m} A_{\mathrm{m}}+\rho_{f} A_{\mathrm{f}}\right) C_{e s}} \frac{d V}{d t} \underset{+\rho_{f} A_{\mathrm{f}} C_{e s}\left(U_{l}\right)^{2}}{\frac{\partial^{2} y}{\partial x^{2}}=-K A G} \psi \\
& \text { - Bending along } \mp_{C_{e}}, \\
& \frac{d M}{d t} \pm{ }_{\left(\rho_{m} I_{\mathrm{m}}+\rho_{f} I_{\mathrm{f}}\right) C_{e}} \frac{d \psi}{d t}= \pm{ }_{C_{e}} Q
\end{aligned}
$$

In which the wave speeds are equal to; 
Citation: Ahmed Al-Rajihy and Mohanned Kadhom, 2018. Analysis of Bending Response of Tubes Conveying Fluid by the Method of Characteristics. Advances in Natural and Applied Sciences., 12(2): 13-20.

$$
C_{e}= \pm \sqrt{\frac{E I_{m}}{\left(\rho_{m} I_{m}+\rho_{f} I_{f}\right)}}
$$$$
C_{e s}=
$$$$
\frac{2\left(\rho_{m} A_{m}\right) \times U 1}{\rho_{f} A_{f}+\rho_{m} A_{m}} \pm 0.5 \sqrt{\left(\frac{\rho_{m} A_{m} \times U 1}{\rho_{f} A_{f}+\rho_{m} A_{m}}\right)^{2}+4 \frac{K G A}{\rho_{f} A_{f}+\rho_{m} A_{m}}}
$$

The characteristic equations, (7) and (8), can be integrated along the lines $L^{\prime} P \& R^{\prime} P$ in case of shear wave and along $R P \& L P$ in case of bending wave as illustrated in Fig. 3. Using central difference expressions and linear function to integrate the terms on the right hand side of (7) and (8); the following relations are obtained:

- The main equations for shear are;

$$
\begin{aligned}
& \left(Q_{P-} Q_{L^{\prime}}\right)+\left(\rho_{m} A_{\mathrm{m}}+\rho_{f} A_{\mathrm{f}}\right) C_{e s L}\left(V_{P}-V_{L^{\prime}}^{\prime}\right)+\rho_{f} A_{\mathrm{f}} \operatorname{Ces}\left(U_{l}\right)^{2} \frac{\partial^{2} y}{\partial x^{2}}=\frac{-K G A}{C_{e S L}} \frac{\left(\psi_{P}+\psi_{L}^{\prime}\right)}{2} \Delta x \\
& -\left(Q_{P-} Q_{R^{\prime}}\right)-\left(\rho_{m} A_{\mathrm{m}}+\rho_{f} A_{\mathrm{f}}\right) C_{e s R}\left(V_{P}-V_{R^{\prime}}\right)+\rho_{f} A_{\mathrm{f}} \operatorname{Ces}\left(U_{l}\right)^{2} \frac{\partial^{2} y}{\partial x^{2}}=\frac{-K G A}{C_{e S L}} \frac{\left(\psi_{P}+\psi_{R}^{\prime}\right)}{2} \Delta x
\end{aligned}
$$

- $\quad$ The main equations for moments are;

$$
\begin{gathered}
\left(M_{P}-M_{L}\right)-\left(\rho_{m} I_{\mathrm{m}}+\rho_{f} I_{\mathrm{f}}\right) C_{e}\left(\psi_{P}-\psi_{L}\right)=-\frac{\left(Q_{P}+Q_{L}\right)}{2} \Delta x \\
\left(M_{P}-M_{R}\right)+\left(\rho_{m} I_{\mathrm{m}}+\rho_{f} I_{\mathrm{f}}\right) C_{e}\left(\psi_{P}-\psi_{R}\right)=+\frac{\left(Q_{P}+Q_{R}\right)}{2} \Delta x
\end{gathered}
$$

Boundary Conditions:

At the boundary points such as point B in Fig. 4, only forward or backward characteristic equations for each type of wave can be obtained. The stipulation of a boundary condition enables a solution to be obtained. The second equation must be therefore provided to describe the boundary and should be solved simultaneously with the characteristic equation. At a fixed end for instance, the velocities (axial, lateral and angular) are stipulated at the fixed end, i.e. $U_{p}=U(t)$, $V_{p}=V(t)$ and $\Psi_{=}^{\Psi} \Psi_{(t) \text {. Else the velocities are equal to zero. The unknown forces and bending moment can be obtained from the appropriate characteristic }}$ equations.

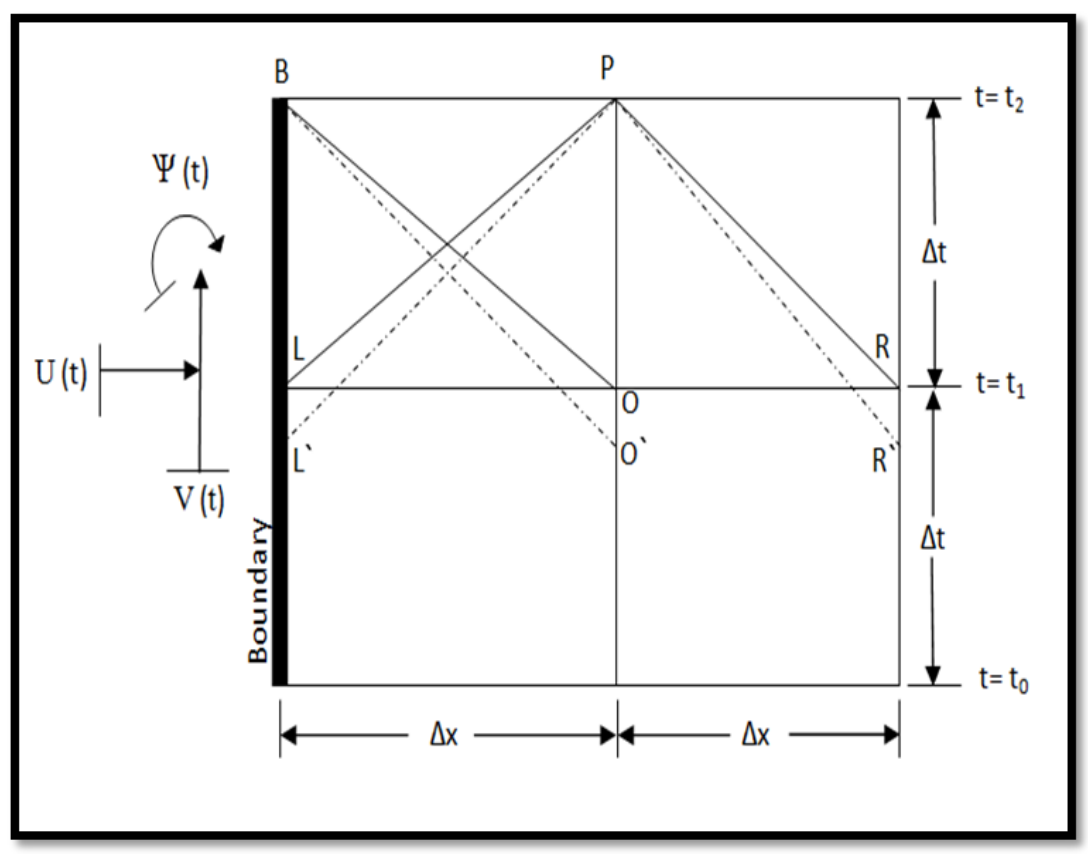

Fig. 4: Fixed end boundary conditions.

\section{RESULTS AND DISCUSSION}

The theoretical calculations and experimental work are carried out according to the properties of the materials and values of the parameters given in Table I. 
Citation: Ahmed Al-Rajihy and Mohanned Kadhom, 2018. Analysis of Bending Response of Tubes Conveying Fluid by the Method of Characteristics.

Advances in Natural and Applied Sciences., 12(2): 13-20.

Table 1: Properties and values of parameters used in this work

\begin{tabular}{|l|l|}
\hline Property or parameter & Value \\
\hline Modulus of elasticity of tube & $190 \mathrm{GPa}$ \\
\hline Ultimate stress & $375 \mathrm{MPa}$ \\
\hline Elongation & $22 \%$ \\
\hline Poisson's ratio & 0.3 \\
\hline Inner tube diameter & $12.2 \mathrm{~mm}$ \\
\hline Tube thickness & $2.5 \mathrm{~mm}$ \\
\hline Tube density & \\
\hline Fluid & \\
\hline
\end{tabular}

Figures 5, 6 and 7 show the bending moment response of a tube subjected to a lateral impact force of $50 \mathrm{~N}$ applied at the free end of the tube. The bending moment response is calculated at three points along the tube, $\mathrm{p}_{1}, \mathrm{p}_{2}$ and $\mathrm{p}_{3}$. These figures are plotted for three values of flow velocities of $0,0.543$ and 1.087 respectively. The effect of flow velocity on value of bending moment response at the root of the tube, point $\mathrm{p}_{3}$, is illustrated in Fig. 8. From these figures it is seen that increasing the flow velocity has the effect of decreasing the value of bending moment response. This trend can be elaborated as; increasing the flow velocity has a damping effect due to the Coriolis term appeared in (2) which works as an energy sink.

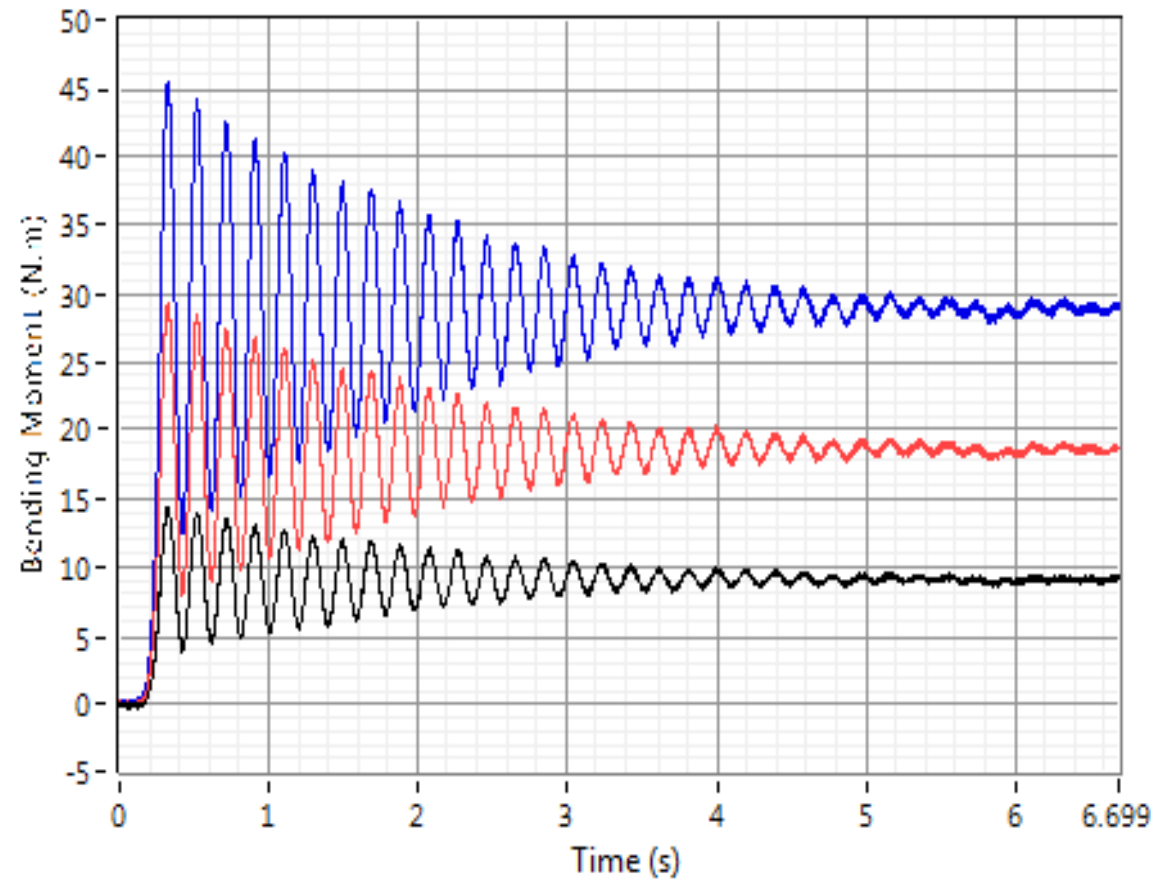

Fig. 5: Bending moment response in time domain at different positions of pipe subjected to $50 \mathrm{~N}$ force applied at the free end for $0 \mathrm{~m} / \mathrm{s}$ flow velocity.

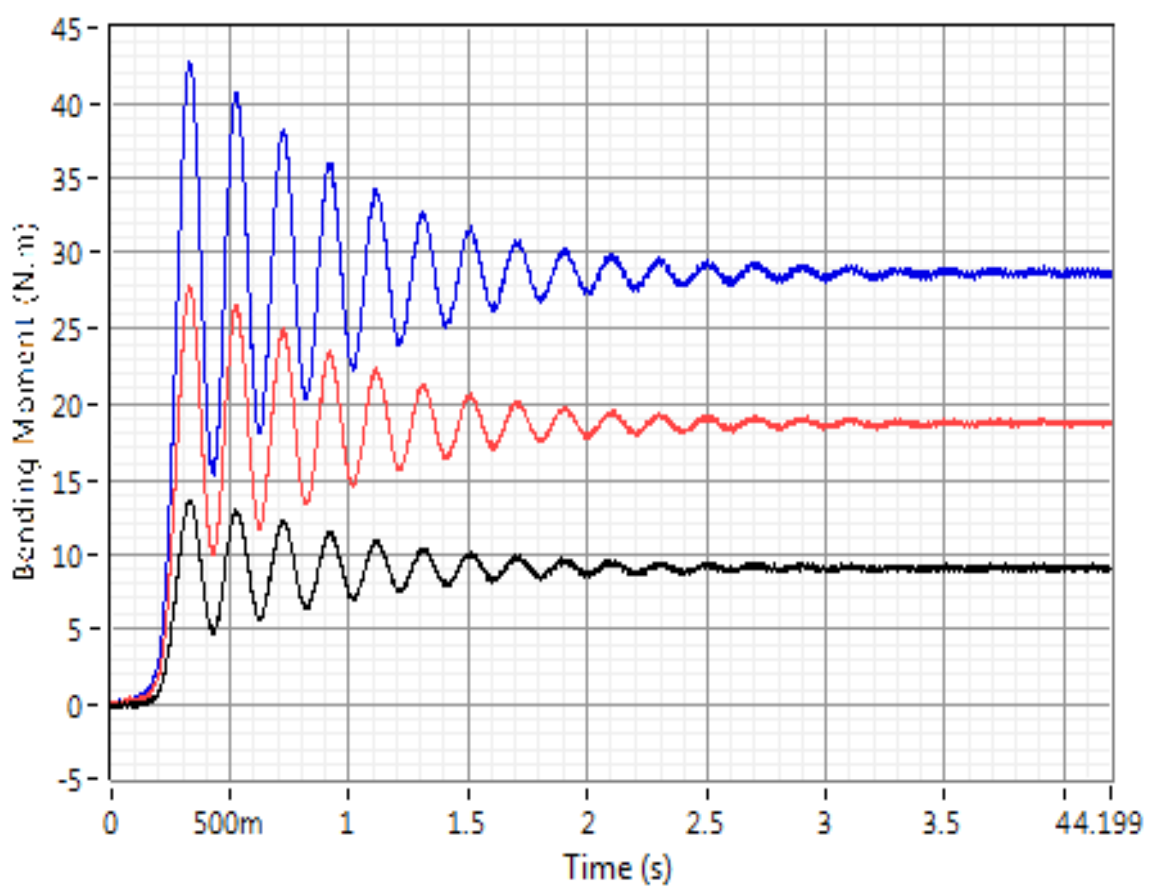

Fig. 6: Bending moment response in time domain at different positions of pipe subjected to $50 \mathrm{~N}$ force applied at free end for $0.544 \mathrm{~m} / \mathrm{s}$ flow velocity. 


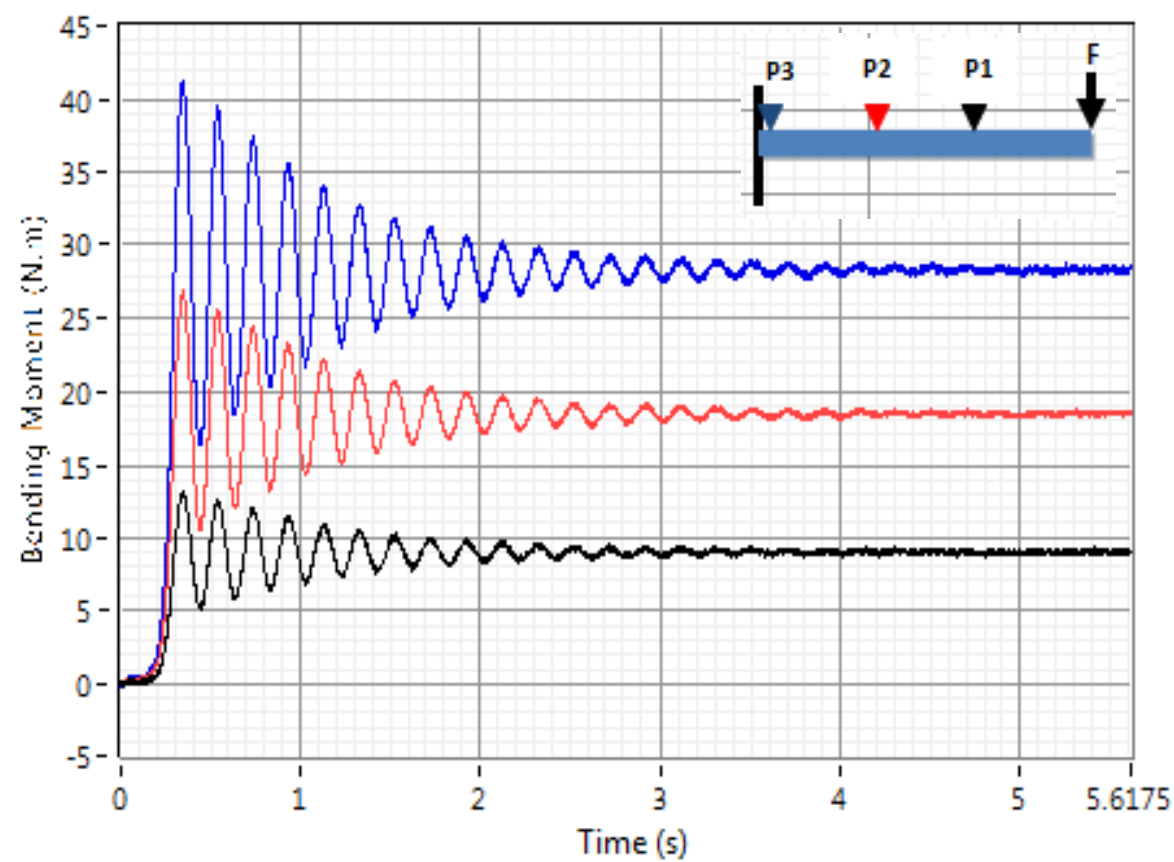

Fig. 7: Bending moment response in time domain at different positions of pipe subjected to $50 \mathrm{~N}$ force applied at free end for $1.087 \mathrm{~m} / \mathrm{s}$ flow velocity.

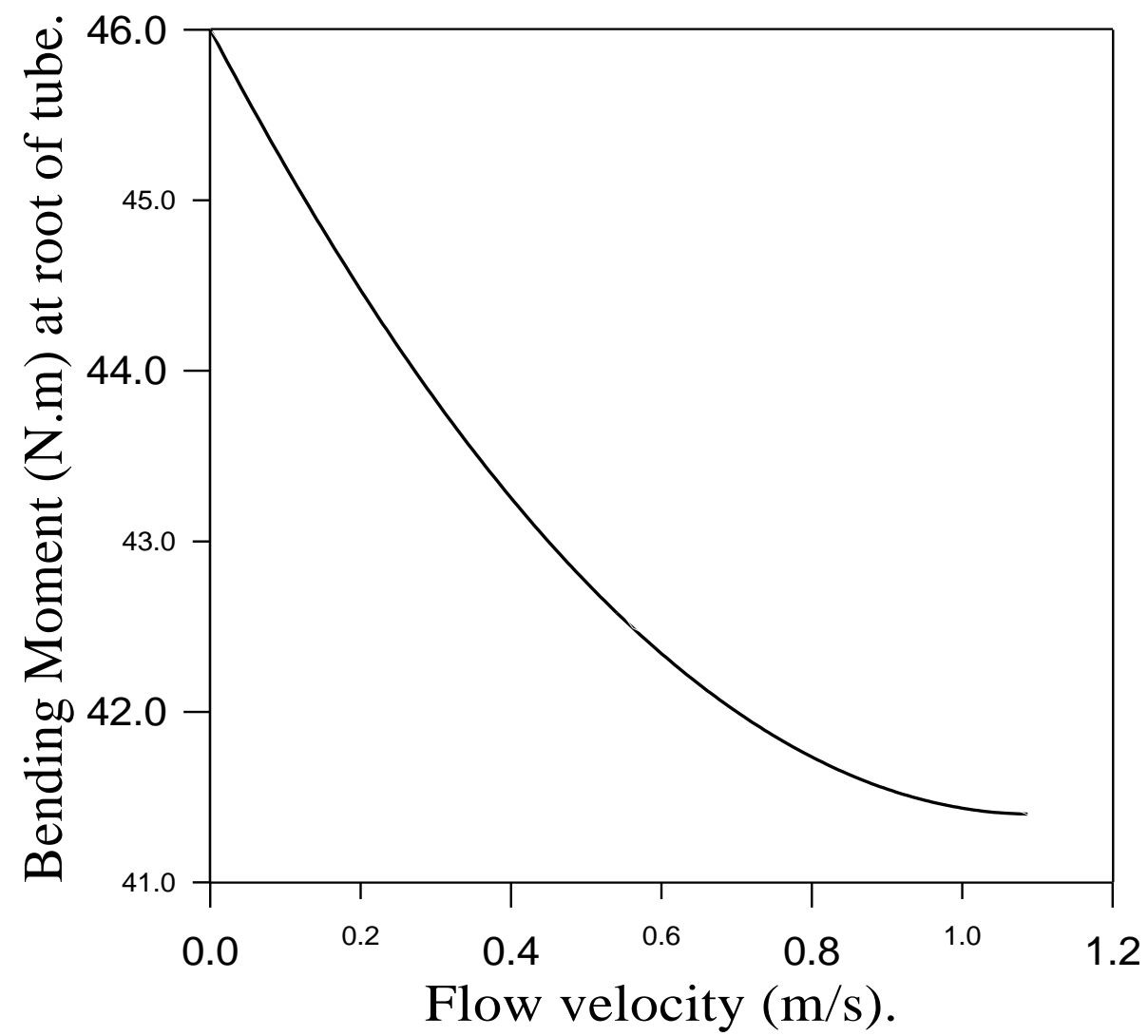

Fig. 8: Effect of Flow rate on bending moment response at root of tube, exciting force is $50 \mathrm{~N}$ applied at free end.

The effect of flow velocity on the time required to get $90 \%$ attenuation of tube tip displacement is shown in Fig. 9. It is seen that the noticeable effect of flow velocity on displacement attenuation is up to $0.8-1 \mathrm{~m} / \mathrm{s}$, then after this velocity the effect of flow velocity died out. This behavior belongs to the fact that increasing the flow velocity cause damping to the tube response, then the increase of flow velocity greater than a certain value may cause excitation to the tube due to the turbulence effects, which can be considered as an energy source. 


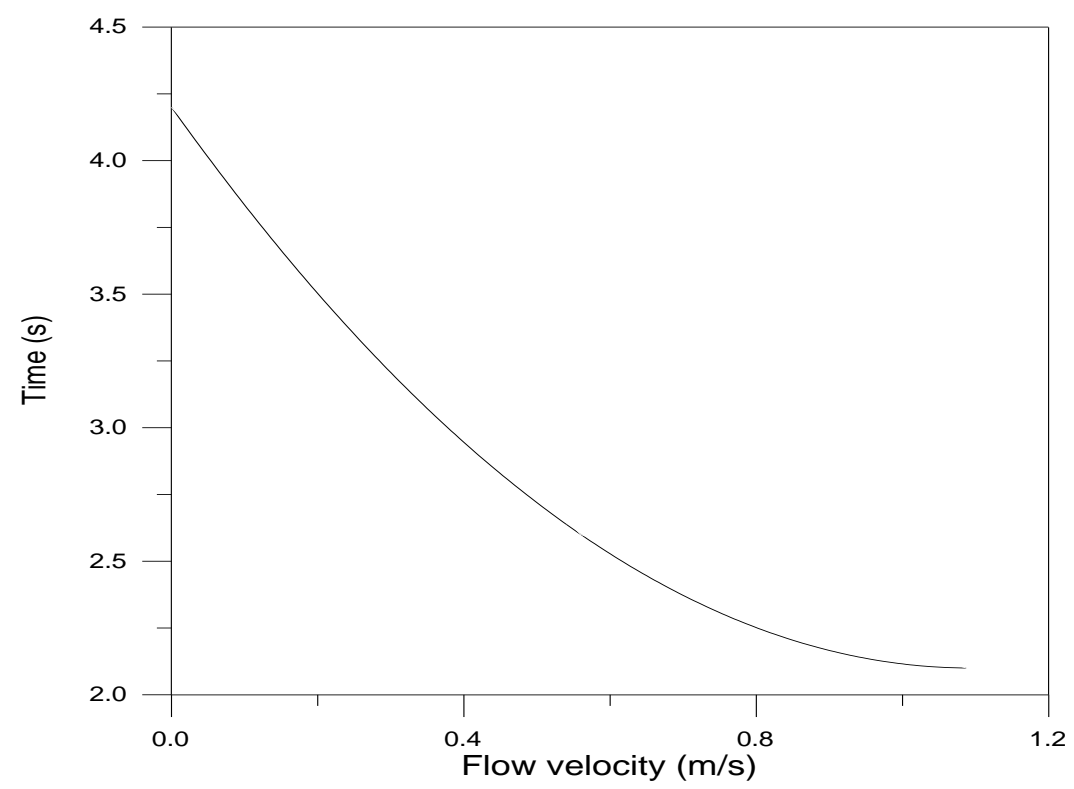

Fig. 9: Effect of Flow velocity on time required to get $90 \%$ attenuation in displacement amplitude.

Figure 10 shows some experiments done on cantilever tube conveying water at velocity of $0.543 \mathrm{~m} / \mathrm{s}$ subjected to lateral impact force of $50 \mathrm{~N}$ acts at the tube tip. This experiment carried out as a verification to theoretical analysis, there is an acceptable agree between the experiments and the theoretical vales given in Figs. 5 to 7.

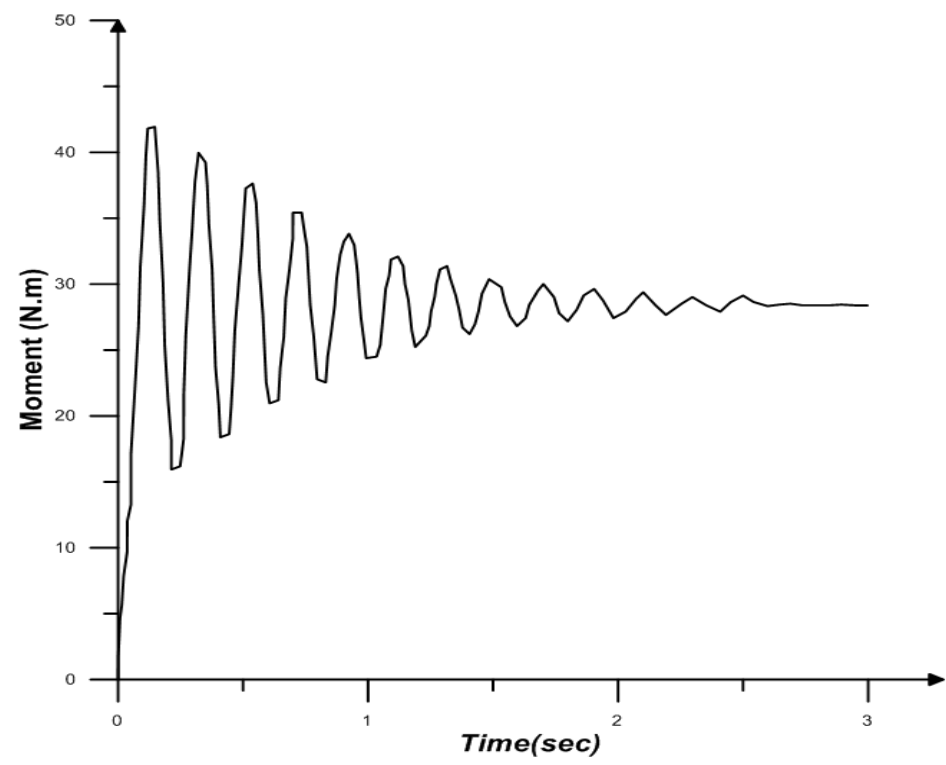

Fig. 10: Experimental bending moment response of cantilever tube subjected to lateral impact force of $50 \mathrm{~N}$, measured at tube root.

\section{CONCLUSIONS}

Through the results presented in this in this study, the following conclusions have been drawn;

1- The method of characteristics (MOC) is efficient to simulate transient response of fluid-structure interaction systems subjected to any type of loading, which is the contribution of this work.

2- Increasing the fluid flow velocity has the effect of damping the bending moment response to about $9 \%$, and this effect increased with increasing the flow velocity within the steady range.

3- Increasing the fluid flow velocity results in decreasing the time required to attenuate the amplitude of bending moment response by $48 \%$.

4- The main effectiveness of fluid flow on the tube dynamics is caused by Coriolis component, which depends on the flow velocity and tube lateral velocity.

It is recommended to use the method of characteristics to study the dynamics of tubes conveying gases and/or tow phase flow.

\section{REFERENCES}

[1] Shima S, Mizuguchi T. 2001. Dynamics of a tube conveying fluid. arXiv preprint nlin/0105038. May 16 .

[2] Ritto TG, Soize C, Rochinha FA, Sampaio R.2014 Dynamic stability of a pipe conveying fluid with an uncertain computational model. Journal of Fluids and Structures. Aug 1;49:412-26.

[3] A. C. Jan Luczko, 2014. Parametric vibrations of pipes induced by pulsating flows in hydraulic systems jan łuczko, andrzej czerwiński, J. Theor. Appl. Mech., 52(3) 719-730.

[4] Ashley H, Haviland G.1950. Bending vibrations of a pipe line containing flowing fluid. Journal of Applied Mechanics-Transactions of the ASME. Jan 1;17(3):229-32.. 
[5] G. W. Housner, 1952. Bending vibrations of a pipe line containing flowing fluid, Journal of Applied Mechanics, 205-208.

[6] Z. W. Zhang Xi-de, Du Tao, 1993. Correction for housner's equation of bending vibration," Applied Mathematical Mechanics, 14(2), 159-160.

[7] A. A. H. Al-Rajihy, 1995. Thermally induced vibrations of continuous pipes conveying fluid with mispositioned support, 14(5), 33-41.

[8] A. Al and K. Kardsheh,2002. "Flow - Induced Vibration of Y - Shaped Tube Conveying Fluid, 2002, Flow Induced Vibration of a Y-Shaped Tube Conveying Fluid, Electronic Journal «Technical acoustics» 2 8.1-8.12, Http://Webcenter.Ru/Neeaa/Ejta/ 8.1-8.12.

[9] H. U. A. Al-rajihy, Ahmed A,2010. The dynamical behavior of y-shaped tubes conveying fluid, ASME 2010 10th Biennial Conference on Engineering Systems Design and Analysis, July 12-14, Istanbul, Turkey, ISBN 978-0-7918-4916-3.

[10] L. Liu and F. Xuan, 2010. Flow-induced vibration analysis of supported pipes conveying pulsating fluid using precise integration method, Mathematical Problems in Engineering, 2010, 1-15

[11] R. A. Ibrahim, 2010. Overview of Mechanics of Pipes Conveying Fluids - Part I : Fundamental Studies, Journal of Pressure Vessele Technology, 132, $1-32$.

[12] R. W. Leorand and B. Budiansky, 1954. On travelling waves in beams, Rep. No. 1173, Langley Aeranuatical Laboratory, 1954.

[13] A. T. A. A. E. VARDY, 1989. Method of characteristics analysis of one-dimensional members," Journal of Sound and Vibrations, 129 (3), 477-487.

[14] P. C. Chou and R. W. Mortimer.1967. Solution of One-Dimensional Elastic Wave Problems by the Method of Characteristics. Journal of Applied Mechanics, 34, 745-750.

[15] S. K. G. M. M. Almousawi, H. R. Harrison, 1988. On numerical solution methods for flexural waves in stepped beams, International Journal of Engineering, Sciences, 7(3), 327-343.

[16] Al-Da'ami, H.H., Al-Rajihy, A.A. and Fadhel, E.Z., 2018. Large Angle Bending Behavior of Curved Members Using The Method of Characteristics. Al-Khwarizmi Engineering Journal, 4(4), pp.91-105. 